\title{
Effect of male provisioning on the parental behavior of female Boreal Owls Aegolius funereus
}

\author{
Markéta Zárybnická* and Jiří Vojar
}

\begin{abstract}
Background: Sex-specific parental roles of most raptors allow mates to cooperate during breeding; while females incubate and brood, males provide food. If one partner fails in its parental duties, however, sex-specific parental roles can limit the ability of each sex to carry out the role normally performed by its partner. We observed the effect of male food provisioning on female parental care in Boreal Owls Aegolius funereus using cameras at 12 nests in western Finland in 2005. We compared the parental care of eight females in nests with a high male feeding rate (successful nests) with that of the females in four nests with a low or zero male feeding rate (failed nests).

Results: Females brooded more intensively in nests where males provided sufficient food for the family. These females continually stayed with the young until the late brooding stage (18 days after hatching). After completing the brooding period (21 days after hatching), they either no longer visited their nests or began to provide food to their young together with males. Females exposed to a low or zero male feeding rate left their young for long periods without brooding during the early brooding stage (8 days after hatching) and provisioned nestlings at a mean rate of $0.6 \pm 0.8$ prey items/night. As a consequence, all of these nesting attempts failed. One female that was widowed 21 days after hatching stopped brooding and began food provisioning alone, but only one of six young successfully left the nest. Body masses of females in successful and unsuccessful nests were similar, indicating that females in nests with insufficient provisioning did not markedly suffer from a lack of food.

Conclusions: Female Boreal Owls adjusted their parental care based on the level of parental effort of their mates and the nesting phase. The nesting attempts, in which males did not provide enough food for the family during the early brooding stage, failed. We concluded that bi-parental care in northern populations of Boreal Owls is essential until brooding is completed.
\end{abstract}

Keywords: Parental care; Food provisioning; Sex roles; Sexual conflict; Nest desertion

\section{Background}

Bi-parental care occurs in most monogamous bird species with altricial or semi-precocial young (Lack 1968; Clutton-Brock 1991; Székely et al. 2007). Such birds exhibit more or less divided parental duties during nesting; on the one hand, there are species in which both males and females cooperate in incubation, brooding, food provisioning, or nest defense (e.g., waders, gulls, auks, pigeons, and passerines), and on the other hand, there are species in which males and females have strictly divided parental task; females usually incubate and brood, while males provide most food for the young and female (e.g., most diurnal raptors and owls).

\footnotetext{
* Correspondence: zarybnicka.marketa@seznam.cz

Faculty of Environmental Sciences, Czech University of Life Sciences Prague, Kamýcká 129, Prague 16521, Czech Republic
}

Bird species with sex roles that are not strictly specialized and with similar body sizes for both sexes have shown that one-parent care may occur early in the nestling period, and thus either both parents or at least one parent is able to compensate for a task of the missing partner (e.g., Snow Buntings Plectrophenax nivalis, Lyon et al. 1987; Spanish Sparrow Passer hispaniolensis, Marques 2004; Northern Flicker Colaptes auratus, Wiebe 2005, 2010; Rock Sparrow Petronia petronia, Griggio and Pilastro 2007; Penduline Tit Remiz pendulinus, van Dijk et al. 2007). In contrast, studies performed on birds with reversed sexual size dimorphism (RSD) and distinctly divided sex roles (mainly hawks, falcons, and owls) suggested that female raptors will desert a nest when their mates die or provide limited parental care (Newton 1979; Korpimäki 1981; Mikkola 1983; Newton et al. 1983;

\section{实 Springer}


Bowman and Bird 1987; Simmons et al. 1987). Rare observations of raptors and owls, however, indicate that one parent is able to partly compensate for mate failure in its parental duties shortly after hatching (Bowman and Bird 1987; Kunstmüller 1994, 1995, 2010; Peške, unpubl. data on Sparrowhawks). However, there is no solid information as to under what conditions a raptor or owl parent would substitute the duties of its mate and how the contribution of one mate affects the parental effort of the other mate.

Boreal Owls Aegolius funereus show highly differentiated sex roles and a marked RSD during the breeding period; the female is approximately $30 \%$ to $40 \%$ heavier (mean male vs. female body mass, 102 vs. $170 \mathrm{~g}$ ) and has on average $5 \%$ longer wings than the male (Korpimäki 1981; Korpimäki and Hakkarainen 2012). While the female incubates eggs and broods young for 3 to 4 weeks after hatching (i.e., the brooding period, Korpimäki 1981; Zárybnická 2009a), the male provides nearly all of the food for the female and young (Korpimäki 1981; Eldegard and Sonerud 2009; Zárybnická 2009a). During this time, the female typically leaves the nest for a few minutes each night in order to defecate, regurgitate the remains of food, or for preening, and usually returns to the nest without prey (Korpimäki 1981; Zárybnická 2009a). The male, however, almost always arrives at the nest with prey (Korpimäki 1981; Zárybnická 2009a, b; Zárybnická et al. 2009). After the brooding period, females may either help males in providing food for the young or desert them (Eldegard and Sonerud 2009; Zárybnická 2009a; Korpimäki et al. 2011). When a female deserts, its mate compensates for the absent female's contribution and continues to care for the nestlings (Korpimäki 1981; Zárybnická 2009a; Eldegard and Sonerud 2012) and fledglings until they become independent (6 to 7 weeks after fledging, Eldegard and Sonerud 2012). Males can be polygynous and simultaneously pair with two or even three females (Carlsson et al. 1987; Carlsson and Hörnfeldt 1989; Korpimäki 1991). Although clutch sizes of primary and secondary/ tertiary females do not differ, the latter females produce significantly fewer and lighter fledglings than the primary or monogamous females or their nesting attempt may even fail due to the low food provision rate by males (Korpimäki 1991; Zárybnická, unpublished data). There is no detailed information on whether poor food provision by males affects the parental effort of females during the brooding period or if females can substitute the duties of their partner.

We investigated bi-parental care by Boreal Owls in western Finland and, specifically, care responses of females during the brooding period according to various male provisioning rates. Using a relatively recently developed methodological approach (e.g., Reif and Tornberg
2006; Nuka et al. 2011) of continuous nest recording with a camera system, we obtained data on the feeding rate of males and time spent away from the nest and the provisioning rate by females. We tested the following hypotheses: (1) females whose mates provide sufficient food for their family brood more intensively than females exposed to insufficient male provisioning, (2) females whose mates fail in food provisioning stop brooding, and their nesting attempts fail, and (3) because the female is dependent on provisioning by the male at time of brooding (Korpimäki 1981; Eldegard and Sonerud 2009; Zárybnická 2009a), we expect that the body mass of females in nests with insufficient food provisioning by males are lower than that of the females in nests with a high male feeding rate.

\section{Methods}

\section{Study area}

Our study was conducted in April to July 2005 in the Kauhava region of western Finland $\left(63^{\circ} \mathrm{N}, 23^{\circ} \mathrm{E}\right.$; elevation 50 to $110 \mathrm{~m})$, an area of about $1,300 \mathrm{~km}^{2}$. Habitats consisted of a mosaic of boreal forests, mainly Norway spruce Picea abies and Scots pine Pinus sylvestris, agricultural fields, and peatland bogs. During 2005, 470 nest boxes were present in our study area, and 75 (16\%) were occupied by Boreal Owls. Most nest boxes were squareshaped with an inner width range of 17 to $22 \mathrm{~cm}$, a height of 50 to $60 \mathrm{~cm}$, and a diameter of the opening of 8 to $10 \mathrm{~cm}$ (Korpimäki 1984). They were usually installed 5 to $7 \mathrm{~m}$ above the ground.

\section{Food abundance}

At our study site, densities of vole populations fluctuate in 3-year cycles (Korpimäki et al. 2005). When this study was conducted, 2005 was an increasing year in the vole cycle with intermediate small-mammal abundances during the breeding season; the number of small mammals trapped was $13.3 \pm 3.0$ individuals/100 trap nights (bank voles Myodes glareolus 48.2\%, sibling voles Microtus rossiaemeridionalis $16.9 \%$, and common shrews Sorex araneus $16.3 \%$ were the most commonly trapped species) (Zárybnická et al. 2012).

\section{Breeding data}

We collected breeding data by inspecting the nest boxes ( $n=470$ ) during the onset of the breeding period, i.e., at the end of March to April (Korpimäki and Hakkarainen 1991). Occupied nest boxes were revisited 1 to 3 times/ week to count the number of eggs, hatchlings, fledglings, and stored prey. Nest boxes which were empty during the first visit were revisited about 1 month after the initial check to locate nests of pairs with a late onset of reproduction. Nests were considered successful if at least one young fledged. For failed nests, we considered a lack 
of food as the cause of nest failure if no prey were found during nest visits (every 5 to 10 days) and/or dead young or their remains were present. Nest predation by pine martens Martes martes mainly occurs during the incubation period, in which case, destroyed eggs were found in the nest or close to the nesting tree. In addition, marten hair and scat were found on the roofs of nest boxes, in the nest boxes, or close to the nesting tree (Korpimäki 1981; Korpimäki and Hakkarainen 2012). The category of other unknown reasons for nest failure included cases for which no apparent cause for female nest abandonment was identified (no predation by martens or no food scarcity detected) and other reasons (e.g., disturbances, severe weather, parent mortality, or abandonment) might have played a role.

\section{Camera nests}

Male and female parental care was recorded using a camera system at 12 nests (16\% of the 75 nest boxes used by Boreal Owls) from 21 April to 14 July. In order to identify parents (i.e., tagging), we caught males by placing a $10 \times$ $10 \times 25-\mathrm{cm}$ wooden trap in front of the opening of the nest box (Korpimäki 1981). We caught and identified 7 of 12 males. Females were caught in their nest boxes by closing the entrance hole by hand or with a long-handled net during the brooding period (mean, $9.4 \pm 3.8$ days after hatching of the oldest young). We ringed, weighed, and determined the age of all females using the molt pattern of primary feathers (as 1, 2, 3 years old, or 'older than 3 years' as described in Hörnfeldt et al. 1988; birds older than 3 years were counted as 4 years old in computing the average female age).

Nests were continually monitored using a camera system integrated into the nest boxes (Bezouška et al. 2005) from the hatching period to the end of each nestling period (mean, $16.3 \pm 8.0$ days/nest). Because Boreal Owls exhibit hatching asynchrony with hatching spans that average 6 to 7 days (Korpimäki 1981, Valkama et al. 2002), both eggs and hatched nestlings were found at nests at the time of camera installation. We recorded the actual foraging situation at these nests at the time of camera installation via the number of nestlings hatched and the number of stored prey items. We had three camera boxes; thus, we could simultaneously monitor three nests. The equipment we used to monitor the parental feeding effort consisted of a camera (DECAM, SINIT, Czech Republic), a passive integrated transponder (PIT) tag reader device (PS02, ELVIS, Czech Republic), a movement infrared detector (KS96, KOTLIN, Czech Republic), and infrared lighting (IR diodes, SFH 485-2 880 $\mathrm{nm}$, SOS electronic, Czech Republic). The camera viewfinder was installed inside the nest box opposite the opening. The camera device and chip reader device were installed in a special wooden box on the roof of the nest box. Each time an owl entered the nest box, the IR motion detector triggered the camera, taking digital images of the owl in the nest box entrance ( $n=1$ to 3 pictures, 1,024 pictures could be stored in total). During the night, the opening was illuminated by infrared diodes at the moment the photos were made by the camera. To determine which individual entered or left the nest box, adults (12 females and 7 males) were fitted with a PIT tag ring (BR chip ring, BENZING, Schruns, Austria, primarily used for homing pigeons). The PIT tag reader (circle aerial with a $12-\mathrm{cm}$ diameter) was integrated into the entrance hole of the nest box and registered all movements of marked individuals in and out of the box. For camera boxes, we randomly chose among suitable nest boxes (i.e., boxes where it was possible to remove the old box, appropriate timing, and avoiding boxes located close to roads and paths to avoid attracting the attention of members of the public to the camera boxes). Upon finding a suitable nest, we replaced the old box with a camera box (at the time of late incubation or hatching). No female abandoned her nest as a result of nest box transfer. The entire camera system was powered by a 60-Ah accumulator (DELPHI, AUTO Štangl, Czech Republic) and changed every 6 to 8 days.

\section{Statistical analysis \\ Basic breeding data}

Possible differences in clutch sizes and numbers of fledglings between camera and non-camera nests and differences in clutch sizes between successful and unsuccessful nests were calculated using the non-parametric Wilcoxon rank-sum test.

\section{Camera nests}

To compare the numbers of nestlings and stored prey items (as response variables) between successful and unsuccessful camera nests at the time of camera installation (with breeding success as an explanatory variable), we used two separate generalized linear models (GLMs) with a Poisson distribution. Because the age of the oldest young varied among nests at the time of nest inspection, we used this factor in all models as a covariate. Body masses and ages of females (as response variables) at successful and unsuccessful nests were also compared using a GLM. Due to the skewed distribution function, we used a gamma distribution for both response variables. Because the body mass of a female decreases during the breeding period (Korpimäki 1981), we used the age of the oldest young at the time females were weighed as a covariate.

\section{Food provisioning}

To compare feeding rates of males and females at successful and unsuccessful nests monitored by cameras 
(with breeding success as an explanatory variable), we built two separate generalized linear mixed models (GLMMs) with the lmer function as part of the lme4 package (Crawley 2007) in R statistical software (R Development Core Team 2009) and a Poisson distribution of both response variables. The response variable (i.e., the feeding rate) was expressed as the number of prey items delivered by the male or female during a certain night. To avoid pseudoreplication resulting from repeated measurements at each nest, we used the identity of the nest as a variable with a random effect. Because the prey delivery rate increases with nestling age (Zárybnická et al. 2012), we used the age of the oldest young as a covariate in both models. Furthermore, due to the negative correlation between feeding rates of males and females (Spearman's rank correlation: $r_{\mathrm{s}}=-0.3, p<0.001$ ), we compared female feeding rates at successful and unsuccessful nests after controlling for the male feeding rate and vice versa, placing the other factor in the model as the covariate.

\section{Female brooding}

We compared the number of times females left their nest and the time spent by females away from the nest at successful and unsuccessful nests monitored by cameras, where breeding success was considered an explanatory variable. Due to the absence of over- and underdispersion in the case of the number of times females left their nest, we used a Poisson distribution of this variable. Because the mean $(69.7 \mathrm{~min})$ and variance $(27,314.4 \mathrm{~min})$ of time spent outside the nest by females indicated a huge possible overdispersion and using a quasi-Poisson distribution in the GLMM is impossible, the variable was logarithmically transformed, and then, a Poisson distribution was used. Furthermore, we found that both response variables were positively correlated (Spearman's rank correlation: $r_{\mathrm{s}}=0.62, p<0.0001$ ). We thus compared the number of times females left their nest at successful and unsuccessful nests after controlling for the time spent away from nest and vice versa, placing the other factor in the model as a covariate.

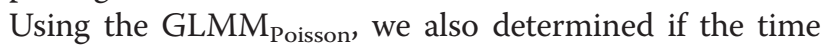
spent away from their nest by females was affected by the age of the oldest young.

For all GLMs and GLMMs performed, the significance of the explanatory variable (breeding success) was tested using deletion tests. Each final GLM and GLMM was checked using analyses of residuals (Crawley 2007). All analyses were computed using $\mathrm{R}$ statistical software, vers. 2.15.0 (R Development Core Team 2009). Values are presented as the mean per nest (clutch size, number of fledglings, and stored prey) or per nest and night (male and female feeding rate) \pm 1 standard deviation (SD).

\section{Results}

\section{All nests}

\section{Basic breeding data}

We collected basic breeding data from 75 total nests. Laying dates of females averaged 4 April \pm 12 days $(n=$ 64 nests), and females laid on average $6.6 \pm 1.2$ eggs ( $n=$ 70 nests). Young fledged from 55 of 75 nests (73\%), and the mean number of fledglings per successful nest was $3.9 \pm 1.6$ young. Twelve (16\%) nests failed because the young starved to death, and eight (11\%) failed for unknown reasons. No nest was depredated. There were no differences in clutch sizes between successful and unsuccessful nests (mean, $6.8 \pm 1.2$ vs. $6.2 \pm 1.2, n=70$ nests; $W=531.5, p=0.08$ ). Simultaneously, we found no differences in clutch sizes (mean, $6.5 \pm 0.7$ vs. $6.6 \pm 1.3, n=70$ nests; $W=333.5, p=0.82$ ) or numbers of fledglings (mean, $3.5 \pm 1.9$ vs. $4.1 \pm 1.6, n=55$ nests; $W=160.5, p=$ $0.51)$ between camera and non-camera nests. Thus, we believe that camera nests were a representative sample for further analyses of parental care.

\section{Camera nests \\ Basic breeding data}

Eight of 12 nests (79\%) monitored by cameras were successful. No difference in clutch sizes (mean, $6.6 \pm 0.7$ vs. $6.8 \pm 0.5 ; W=13.5, p=0.71$ ) was found between successful and unsuccessful camera nests. We also found no difference in numbers of hatched nestlings (mean, $5.1 \pm 0.8$ vs. $4.8 \pm 1.5$; deviation $=0.58, p=0.99$ ) between successful $(n=4)$ and unsuccessful $(n=8)$ camera nests in the early brooding period when the camera equipment was installed (mean, $8.1 \pm 3.1$ days after hatching of the first young). However, owls in successful nests had stored significantly more prey items (mean, $4.5 \pm 2.1$ items) than owls in unsuccessful nests (no prey) at that time (deviation $=5.89, p<0.0001)$.

No difference was found in either body masses (mean, $153.5 \pm 9.8$ vs. $164.1 \pm 14.8 \mathrm{~g} ; F_{1}=0.2, p=0.88$ ) or ages ( $2.3 \pm 1.3$ vs. $2.8 \pm 1.0$ year; $\left.F_{1}=0.1, p=0.82\right)$ of females at unsuccessful and successful nests. Seven males were identified in successful nests, and all males except one were monogamous. The polygynous male provided sufficiently for four fledglings in the primary nest (the nest monitored by a camera), but its second nest failed because of food scarcity.

\section{Food provisioning}

During 945 feeding visits over the brooding period ( $n=$ 126 nights), 12 males delivered a total of 926 prey items, and 12 females delivered 19 prey items. Males at successful nests $(n=8)$ delivered significantly more prey items to their nests than males at failed nests $(n=4,2$ males provided no food during 5 and 3 nights, and the other 2 males delivered 10 and 4 prey items during 9 
and 6 nights, respectively) (mean $=9.3 \pm 4.5$ vs. $0.6 \pm$ 0.9 items/night; $\chi_{1}^{2}=29.6, p<0.0001$, Figure $\left.1 \mathrm{~A}\right)$. In contrast, females at nests with a low or zero male feeding rate (failed nests) more often returned to their nestlings with prey than females at nests with a high male feeding rate (successful nests) (mean, $0.6 \pm 0.8$ vs. $0.1 \pm$ 0.3 prey items/night; $\chi_{1}^{2}=4.8, p=0.03$; Figure $1 \mathrm{~B}$ ).

\section{Female brooding}

Females left the nests on average $2.6 \pm 1.2$ times for a total of $1.6 \pm 2.6 \mathrm{~h}$ each night during the brooding period. Females at unsuccessful and successful nests did not differ in the number of times they left the nest $\left(\chi_{1}^{2}=\right.$ $2.1, p=0.14$, Figure 1C), but females at unsuccessful nests where the male provided insufficient food remained away from their nest longer $\left(\chi_{1}^{2}=6.5, p=0.01\right.$, Figure 1D). We also found that females at both successful and unsuccessful nests spent more time away from nests with an increasing nestling age $\left(\chi_{1}^{2}=7.56, p=\right.$ 0.006 , Figure 2). However, females whose mates provided sufficient food for the family increased their time away from the nest only after the brooding stage (oldest young $>18$ days old), whereas females exposed to a low or zero male feeding rate did so during the early brooding stage (oldest young 8 days old, Figure 2).

\section{End of brooding}

Females at nests with a low or zero male feeding rate stopped providing parental care $11.8 \pm 4.5$ days after hatching of the first young. At that time, only dead young (mean, $2.0 \pm 0.8$ per nest) and a few stored prey items $(0.5 \pm 1.0$ prey items/nest $)$ were found in these nests. Females at nests with a high male feeding rate completed brooding $21.4 \pm 1.5$ days after hatching of the first young and left nests with $4.1 \pm 1.7$ live young and $1.0 \pm 2.8$ prey items.
Three of eight females at successful nests did not visit their nest after the brooding period. Another four females provisioned nestlings (mean, $2.4 \pm 1.9$ prey items/ night) along with their mates $(6.4 \pm 2.2$ prey items/night) until the young fledged. At one successful nest, the male disappeared (reason unknown) when the oldest young was 21 days old; this male had provided more food than any other male (mean, $13.8 \pm 5.3$ prey items/night). The female at this nest subsequently provisioned the young at a rate higher than other females with successful nests (mean, $4.8 \pm 1.2$ prey items/night), but only one young fledged. The mean number of young that fledged from successful nests $(n=8)$ was $3.5 \pm 1.9$.

\section{Discussion}

We found a total of $12(16 \%)$ Boreal Owl nests that failed due to food scarcity; four of these nests were monitored by the camera. At these camera nests, males were absent or provided food at a low rate. In good vole years, the reproductive period of Boreal Owls begins approximately 1 month earlier; clutch sizes are larger than in poor vole years, and $10 \%$ to $20 \%$ of males are polygynous (Korpimäki 1991; Korpimäki and Hakkarainen 1991, 2012). Although polygynous males usually provide sufficiently for their first nests, the breeding success of their secondary nests is poor (Korpimäki 1991). In our study, one polygynous male sufficiently fed its first family (the nest monitored by a camera), but its second nest failed because of food scarcity. We suggest that nests that failed due to food scarcity might have been the second nests of polygynous males.

One could ask why females choose already mated males given that these males are unable to provide sufficient food for second families. Korpimäki (1991) showed that polygynous males sufficiently feed their secondary females during courtship, egg laying, and incubation, but
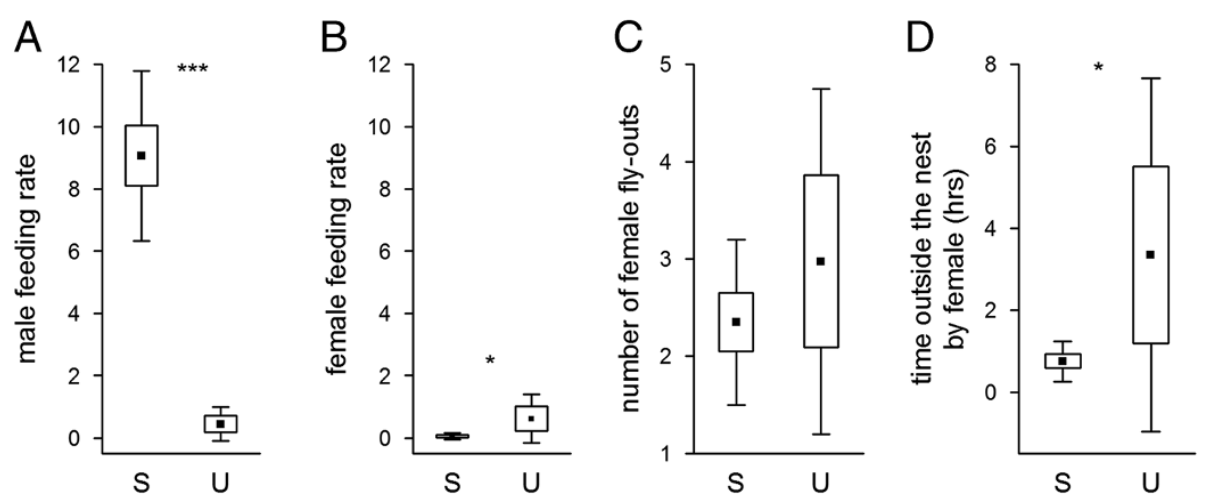

Figure 1 Comparison of male and female food provisioning, female fly-outs, and time spent outside the nest. Comparison of (A) male and (B) female food provisioning (number of prey items delivered to the young), (C) number of female fly-outs from the nest, and (D) time spent outside the nest by the female during the brooding period in successful (indicated by the letter $\mathrm{S}, n=8$ ) and unsuccessful (indicated by the letter $U, n=4$ ) nests. Values are the mean/night \pm SE or SD. Statistical comparisons were made using generalized linear mixed models (GLMMs) with a Poisson distribution of response variables. ${ }^{*} p=0.01$ to $0.03,{ }^{* * *} p<0.0001$. 


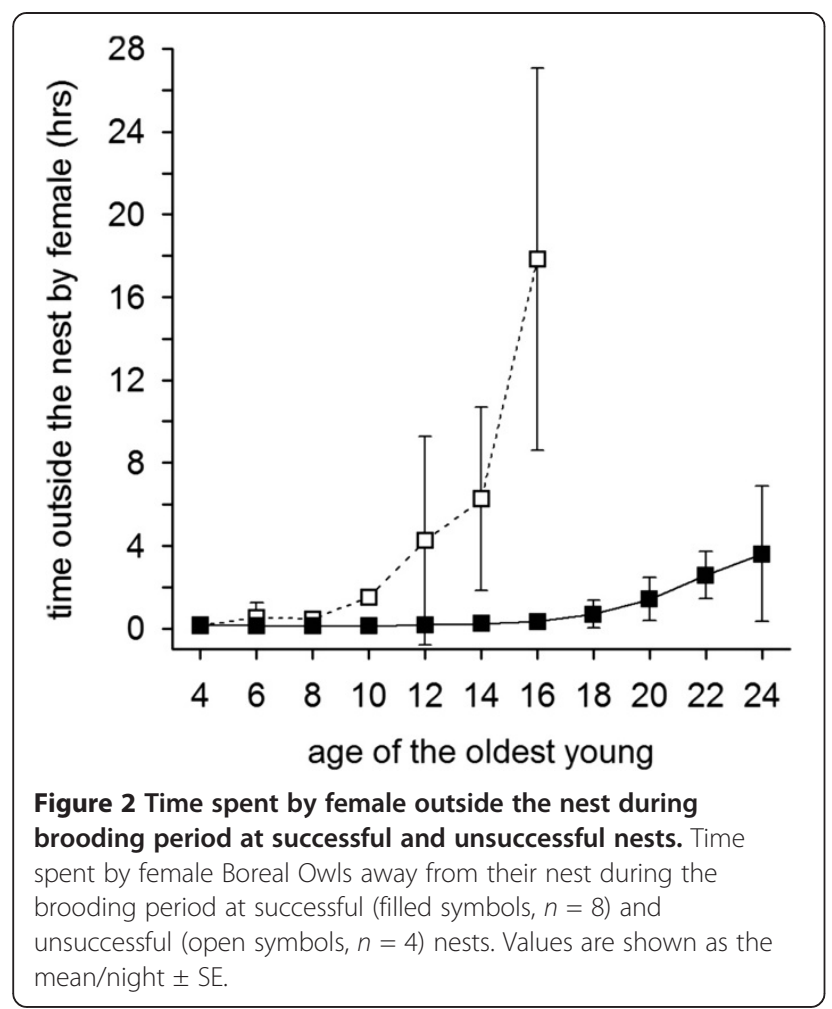

they often fail in provisioning after the young have hatched. Our findings also indicate that males had no trouble feeding their females during incubation but failed in provisioning at the time of nestlings. It was suggested that females of vole-eating birds including the Boreal Owl use provisioning rates during courtship feeding as a cue for mate choice (Altenburg et al. 1982; Simmons 1988; Korpimäki 1991; Palokangas et al. 1992). Already paired Boreal Owl males occupying high-quality territories are able to 'imitate' the provisioning rates at a similar level to an unmated male when a female is choosing a mate (Korpimäki 1991). However, females presumably cannot predict that their mates will provide little food during the nestling period, which results in poor reproduction success of secondary females (Korpimäki 1991). Finally, despite the poor reproductive success of secondary/tertiary nests, polygynous males gain substantial fitness benefits because they produce more fledglings in one breeding season than monogamous males (Korpimäki and Hakkarainen 2012).

According to our first prediction, females $(n=8)$ whose mates provided sufficient food for their family brooded their young more intensively than did females exposed to a low or zero male feeding rate. They left nestlings without brooding only for a few minutes each night until the oldest young was about 18 days old. Thereafter, they increased the time spent outside the nest box, indicating that the young were able to thermoregulate at that time. Moreover, these females usually returned to the nest without prey, suggesting they made no effort to hunt for their offspring. Such results on female parental behavior are consistent with those from successful nests in Central Europe (Zárybnická 2009a). After completing brooding, some females provisioned young with their mates until fledging, but others did not. These results support earlier findings that females may either contribute food to their young in the late nestling period or desert their offspring owing to both re-mating (sequential polyandry) or increasing their own chances of survival until the next breeding season (Eldegard and Sonerud 2009, 2010; Zárybnická 2009a).

Four female Boreal Owls in our study, however, decreased brooding and increased foraging in response to the absence or low feeding rates of males during the early brooding phase (i.e., at a time when the young needed both brooding and food provisioning). These females left their nest for as long as several hours per night, and sometimes came back to the nest with food. Therefore, it is likely that these females attempted to hunt to compensate for the insufficient feeding rates of their mates. However, these females stopped providing at an early stage of the brooding period when the oldest young averaged 11.8 days of age, and thus nesting attempts failed (i.e., our second prediction).

We detected no difference between body masses of females in nests with sufficient and insufficient provisioning by males, which contradicts our third prediction. This fact suggests that females whose males exhibited a low or zero feeding rate did not markedly suffer from a lack of food. They apparently obtained food for their own energy needs but not enough food for the nutritional requirements of their young. This supports the finding that Boreal Owl females put a priority on themselves rather than on their offspring (experimental studies with supplementary food, Eldegard and Sonerud 2010; Santangeli et al. 2012).

Results of this study indicate that Boreal Owl females tried to compensate for the failure of their mates to perform parental tasks but were unable to successfully compensate for insufficient mate provisioning when brooding was obligatory. Similarly, Eldegard and Sonerud (2009) reported a brood where the male deserted and the female deserted shortly thereafter. One of our females, however, although widowed when the oldest chick was 21 days old, managed to fledge one chick. In other raptors, some examples of a parent successfully raising the young alone without his/her mate were also reported (Bowman and Bird 1987; Kunstmüller 1994, 1995, 2010; Peške, unpublished data on Sparrowhawks). Our findings indicate that the stage of the nesting phase can influence whether or not a Boreal Owl female provides single-parent care. Because successful offspring desertion by female Boreal Owls (in the late nesting phase) and male-only care are 
positively related to food abundance (Eldegard and Sonerud 2009; Zárybnická 2009a; Korpimäki et al. 2011), the responses of female owls to low male food provisioning may vary in different environments and particularly under fluctuating food conditions. Similarly, female Eurasian Kestrels Falco tinnunculus and Northern Goshawks Accipiter gentilis adjust hunting efforts and nest attendance to the abundance of their main prey (Tolonen and Korpimäki 1994; Dewey and Kennedy 2001; Riegert et al. 2007). Unfortunately, we have no data to compare female-only parental care in Boreal Owls under different food availability levels.

\section{Conclusions}

We concluded that this study provides rare information on how the contribution of owl males affects the female parental effort. We found that females adjusted their parental care (in terms of brooding intensity and food provisioning) based on the level of parental effort of their mates and the nesting phase. Based on these results, we concluded that at least in the north, bi-parental care in the Boreal Owl seems to be obligatory until the brooding period is completed.

\section{Competing interests}

The authors declare that they have no competing interests.

\section{Authors' contributions}

MZ conceived, and designed the study, collected field data, analysed the data, and wrote the manuscript. JV performed statistical analyses and gave comments on the manuscript. Both authors read and approved the final manuscript.

\section{Acknowledgements}

Many thanks are due to Erkki Korpimäki for providing a foothold in Finland and enabling this research to be undertaken in his study area. We are grateful to J. Zárybnický, M. Griesser, J. Nurmi, and R. Varjonen for their help in the field and to V. Bezouška and P. Děd for technical assistance. This study was supported by the Czech University of Life Sciences Prague (grants nos. $41110 / 1313 / 3156$ and $41110 / 1643 / 6457$ ) and by the Ministry of Education, Youth and Sports of the Czech Republic (FRVS grant no. 41110/1161/1625).

Received: 22 February 2013 Accepted: 18 June 2013

Published: 8 October 2013

\section{References}

Altenburg W, Daan S, Starkenburg J, Zijlstra M (1982) Polygamy in the marsh harrier, Circus aeruginosus: individual variation in hunting performance and number of mates. Behav 79:272-312

Bezouška V, Děd P, Drdáková-Zárybnická M (2005) The automatic system for monitoring of owls' nests. In: ITCE 2005 Conference Abstracts. Technical Faculty, Czech Univ. of Agriculture in Prague, Prague, pp 173-182

Bowman R, Bird DM (1987) Behavioral strategies of American Kestrels during mate replacement. Behav Ecol Sociol 20:129-135

Carlsson BG, Hörnfeldt B (1989) Trigyny in Tengmalm's Owl Aegolius funereus included by supplementary feeding. Ornis Scand 20:155-156

Carlsson BG, Hörnfeldt B, Löfgren O (1987) Bigyny in Tengmalm's Owl Aegolius funereus: effect of mating strategy on breeding success. Ornis Scand 18:237-243

Clutton-Brock TH (1991) The evolution of parental care. Princeton Univ. Press, Princeton

Crawley MJ (2007) The R book. Wiley, Chichester

Development Core Team R (2009) R: a language and environment for statistical computing. R Foundation for Statistical Computing, Vienna
Dewey SR, Kennedy PL (2001) Effects of supplemental food on parental care strategies and juvenile survival of Northern Goshawks. Auk 118:352-365

Eldegard K, Sonerud GA (2009) Female offspring desertion and male-only care increase with natural and experimental increase in food abundance. Proc $R$ Soc B 276:1713-1721

Eldegard K, Sonerud GA (2010) Experimental increase in food supply influences the outcome of within-family conflicts in Tengmalm's Owl. Behav Ecol Sociol 64:815-826

Eldegard K, Sonerud GA (2012) Sex-roles during post-fledgling care in birds: female Tengmalm's Owls contribute little to food provisioning. J Ornithol 153:385-398

Griggio M, Pilastro A (2007) Sexual conflict over parental care in a species with female and male brood desertion. Anim Behav 74:779-785

Hörnfeldt B, Carlsson BG, Nordström A (1988) Molt of primaries and age determination in Tengmalm's Owl (Aegolius funereus). Auk 105:783-789

Korpimäki E (1981) On the ecology and biology of Tengmalm's Owl Aegolius funereus in southern Ostrobothnia and Soumenselkä, western Finland. Biol 13:1-84

Korpimäki E (1984) Clutch size and breeding success of Tengmalm's Owl Aegolius funereus in natural cavities and nest boxes. Ornis Fenn 61:80-83

Korpimäki E (1991) Poor reproductive success of polygynously mated female Tengmalm's Owls: are better options available? Anim Behav 41:37-47

Korpimäki E, Hakkarainen H (1991) Fluctuating food supply affects the clutch size of Tengmalm's Owl independent of laying date. Oecologia 85:543-552

Korpimäki E, Hakkarainen H (2012) The Boreal Owl: ecology, behaviour and conservation of a forest-dwelling predator. Cambridge Univ. Press, Cambridge

Korpimäki E, Norrdahl K, Huitu O, Klemola T (2005) Predator-induced synchrony in population oscillations of co-existing small mammal species. Proc $R$ Soc $B$ 272:193-202

Korpimäki E, Salo P, Valkama J (2011) Sequential polyandry by brood desertion increases female fitness in a bird with obligatory bi-parental care. Behav Ecol Sociol 65:1093-1102

Kunstmüller I (1994) Remarkable parental care of Marsh Harrier Circus aeruginosus. Zpravodaj Jihomoravské pobočky ČSO 2:7-8 (in Czech)

Kunstmüller I (1995) Successful offspring rearing by male Marsh Harrier Circus aeruginosus. Zprávy ČsO 40:45 (in Czech)

Kunstmüller I (2010) Breeding care by the parent birds and the behaviour of young Marsh Harriers Circus aeruginosus during the breeding period. Sluka 7:75-93 (in Czech with English summary)

Lack D (1968) Ecological adaptations for breeding in birds. Methuen Press, London

Lyon BE, Montgomerie RD, Hamilton LD (1987) Male parental care and monogamy in Snow Buntings. Behav Ecol Sociol 20:377-382

Marques PA (2004) Parental care, male desertion, and reproductive success in the Spanish Sparrow, Passer hispaniolensis. Zool Stud 43:123-131

Mikkola H (1983) Owls of Europe. Poyser, Calton

Newton I (1979) Population ecology of raptors. T and AD Poyser, Berkhamsted

Newton I, Marquiss M, Village A (1983) Weights, breeding and survival in European Sparrowhawks. Auk 100:344-354

Nuka T. Morikawa Y, Norman CP (2011) Use of an infrared monitor to record the frequency and timing of parental nest visitation by the Blue Rock Thrush Monticola solitarius. Zool Stud 50:16-23

Palokangas P, Alatalo RV, Korpimäki E (1992) Female choice in the kestrel under different availability of mating options. Anim Behav 43:659-665

Reif V, Tornberg R (2006) Using time-lapse digital video recording for a nesting study of birds of prey. Eur J Wildl Res 52:251-258

Riegert J, Dufek A, Fainová D, Mikeš V, Fuchs R (2007) Increased hunting effort buffers against vole scarcity in an urban Kestrel Falco tinnunculus population. Bird Study 54:353-361

Santangeli A, Hakkarainen H, Laaksonen T, Korpimäki E (2012) Home range size is determined by habitat composition but feeding rate by food availability in male Tengmalm's Owls. Anim Behav 83:1115-1123

Simmons R (1988) Honest advertising, sexual selection, courtship displays and body condition of polygynous male harries. Auk 105:303-307

Simmons RE, Barnard PE, Smith PC (1987) Reproductive behaviour of Circus cyaneus in North America and Europe: a comparison. Ornis Scand 18:33-41

Székely T, Kosztolányi A, Küpper C, Thomas GH (2007) Sexual conflict over parental care: a case study of shorebirds. J Ornithol 148:211-217

Tolonen P, Korpimäki E (1994) Determinants of parental effort: a behavioural study in the Eurasian Kestrel, Falco tinnunculus. Behav Ecol Sociol 35:355-362 
Valkama J, Korpimäki E, Holm A, Hakkarainen H (2002) Hatching asynchrony and brood reduction in Tengmalm's owl Aegolius funereus: the role of temporal and spatial variation in food abundance. Oecologia 133:334-341

van Dijk RE, Szentirmai I, Komdeur J, Székely T (2007) Sexual conflict over parental care in Penduline Tits Remiz pendulinus: the process of clutch desertion. Ibis 149:530-534

Wiebe KL (2005) Asymmetric costs favor female desertion in the facultatively polyandrous Northern Flicker (Colaptes auratus): a removal experiment. Behav Ecol Sociol 57:429-437

Wiebe KL (2010) Negotiation of parental care when the stakes are high: experimental handicapping of one partner during incubation leads to shortterm generosity. J Anim Ecol 79:63-70

Zárybnická M (2009a) Parental investment of female Tengmalm's Owls Aegolius funereus: correlation with varying food abundance and reproductive success. Acta Ornithol 44:81-88

Zárybnická M (2009b) Activity patterns of male Tengmalm's Owls, Aegolius funereus under varying food conditions. Folia Zool 58:104-112

Zárybnická M, Sedláček O, Korpimäki E (2009) Do Tengmalm's Owls alter parental feeding effort under varying conditions of main prey availability? J Ornithol 150:231-237

Zárybnická M, Korpimäki E, Griesser M (2012) Dark or short nights: differential latitudinal constraints in nestling provisioning patterns of a nocturnally hunting bird species. PLOS ONE 7:e36932

doi:10.1186/1810-522X-52-36

Cite this article as: Zárybnická and Vojar: Effect of male provisioning on

the parental behavior of female Boreal Owls Aegolius funereus. Zoological Studies 2013 52:36.

\section{Submit your manuscript to a SpringerOpen ${ }^{\circ}$ journal and benefit from:}

- Convenient online submission

- Rigorous peer review

- Immediate publication on acceptance

- Open access: articles freely available online

- High visibility within the field

- Retaining the copyright to your article

Submit your next manuscript at $>$ springeropen.com 